\title{
Comportamiento de la Regeneración Natural en el Bosque Húmedo Tropical Latifoliado Año y Medio Después del paso del Huracán Félix
}

\author{
German López Calero \\ Bluefields Indian and Caribbean University (BICU)
}

En esta ocasión, y aprovechando el foro forestal que estamos desarrollando en Bilwi, y partiendo de una iniciativa de un grupo de estudiantes y mi persona en conocer un poco qué está pasando en cuanto a la regeneración natural del bosque huracanado por el huracán Félix, nos dimos a la tarea de levantar información para tener elementos básicos que nos indiquen qué es lo que está pasando a un año y medio en estos bosques.

Para esto, como decía anteriormente, en colaboración con un par de estudiantes se levantó una información, en la comunidad El Naranjal, que vamos a ver posteriormente y que al final creo que nos va a llevar a reflexionar sobre lo que hay, lo que está pasando y lo que podría venir con respecto al comportamiento de regeneración ambiental natural del bosque tropical un año y medio después del paso del huracán.

Esta investigación servirá también como fuente de información a los gobiernos regionales, municipales, sociedad, alumnos de las universidades, comunitarios e instituciones del Estado.

El trabajo refleja el comportamiento de la regeneración natural un año y medio después del paso del huracán Félix, en tres estratos principales: fustales para los DAP mayores de $10 \mathrm{~cm}$, latizales con diámetros de cinco a $9.9 \mathrm{~cm}$ y brinzales para plántulas de $0.3 \mathrm{~m}$ a $1.5 \mathrm{~m}$ de altura.

En ese contexto se refiere a la cantidad de regeneración natural por hectárea en cada estrato, referente a conocer si existen especies comerciales en el bosque, lo que garantiza un bosque de alto valor comercial. Todo esto para ver qué está pasando en el contexto de la actividad forestal y para conocer realmente si el bosque en su regeneración tiene o no algún valor

\section{Objetivos}

Los objetivos fueron los siguientes:

- Determinar la densidad de la regeneración natural en el bosque natural húmedo tropical latifoliado huracanado.

- Identificar las especies comerciales, potenciales y no comerciales que tienen presencia en el bosque después del paso del huracán.

\section{Metodología}

Como decía anteriormente, el estudio lo hicimos en 20 ha de bosque afectado por el huracán Félix. En este sito levantamos 20 parcelas, con un muestreo sistemático, dentro de estas parcelas, para:

- Fustales, DAP mayores de $10 \mathrm{~cm}$. Se muestreó un $4.8 \%$.

- Latizales, para árboles cuyos diámetros es de $5 \mathrm{~cm}$ a $9.9 \mathrm{~cm}$. En este caso se muestreó un $0.8 \%$.

- Brinzales, para árboles pequeños cuya altura va de $0.3 \mathrm{~m}$ a $1.5 \mathrm{~m}$. En este caso se muestreó un $0.12 \%$.

Para cada uno de ellos, lógicamente, el tamaño de las parcelas fue diferente partiendo del hecho que fueron 20 parcelas en las 20 ha.

\section{CONCLUSIONES}

En el caso de los fustales, éstos se subdividieron en tres clases diamétricas para ver cómo se correspondían en este sentido; y se pudo observar que la clase diamétrica de 
18 a 20 cm, era la mayor cantidad de árboles que habían quedado después del paso del huracán. Recordemos que cuando se habla de los fustales estamos hablando de los árboles de mayor diámetro y que fueron los que quedaron. Pueden ser que algunos estén partidos, quebrados o en brotes al final del estudio. En esos fustales se pudo identificar un porcentaje de especies por su uso, partiendo de los comerciales. En este sentido se identificó que un 47 por ciento de esas especies eran comerciales; potenciales un 37 por ciento, y los no comerciales 16 por ciento. Quiere decir que ese bosque estaba en condiciones de aprovecharse antes del huracán.

En el caso de los latizales, también se subdividieron en clases diamétricas de 5 a $7.5 \mathrm{~cm}$ y de 7.6 a $9.9 \mathrm{~cm}$. En donde se pudo observar que la mayoría de ellos se encuentran en el rango de 5 a $2.5 \mathrm{~cm}$. Esto demuestra que éstos conformaban el brinzal que existía antes del paso del huracán. En ese sentido, también podemos apreciar que el gran porcentaje del latizal es no comercial, pues hay un porcentaje de un 24 por ciento, y un 5 por ciento de comercial. Podemos observar que en ese bosque, en su regeneración natural, eran muy pocas las especies comerciales hasta el momento del huracán.

En el caso de los brinzales, que son los arbolitos que crecieron después del paso del huracán un año después, nos damos cuenta que hay un diferencia significativa, porque es evidente que hay una gran cantidad de árboles potenciales y comerciales. Partiendo de ese hecho podemos ver que la cantidad de árboles comerciales es significativa, con un 38 por ciento, y un 7 por ciento de potenciales. De allí podemos decir que la mitad de las especies que están surgiendo, de alguna manera tiene un valor comercial, y hay que darle a esto una atención especial. En este sentido debemos implementar acciones encaminadas a que esas especies potenciales que están surgiendo se de desarrollen.

Partiendo de estos datos podemos concluir, de manera general, que los fustales encontrados fueron aquellos que sobrevivieron al huracán y que, de alguna manera, algunos de ellos podrían aportar semillas, si su afectación en cada uno de ellos no fue de gran magnitud. La poca presencia de árboles comerciales en los latizales, no son más que los que existían antes del huracán y que era lo que estaban debajo del dosel de ese bosque. En el caso de los brizales se aprecia una cantidad de árboles comerciales, lo que quiere decir que bajo el dosel de ese bosque existía un sinnúmero de semillas de especies comerciales que no habían germinado, y cuando se provocó el disturbio debido al huracán, empezó a llegarles iluminación y esas semillas comenzaron a germinar. Por esa razón tenemos, podemos decir, suficientes especies comerciales en ese bosque hasta el momento. El camino a seguir para esta regeneración de alto valor será dirigirse a manejo y convertir esta regeneración natural en una regeneración establecida en donde podamos decir que así v a quedar ese bosque. Entonces el manejo es fundamental en este sentido. Los resultados de una falta de ese manejo van a provocar que se opaque el crecimiento de estas especies comerciales y surjan las no comerciales. Y de esta forma tendríamos un bosque de alto valor ecológico, pero de bajo valor comercial.

Esto es en síntesis el resultado de esta investigación en el caso de este bosque en su regeneración natural. 